\title{
Energy Efficient Industrial Parks Cooperation: The Case Study of Fabbrico and Rolo in Reggio Emilia, Italy
}

\author{
Silvia Brunoro ${ }^{\mathrm{a}}$, Giacomo Bizzarri ${ }^{\mathrm{a}}$, Laura Ferrari $^{\mathrm{b}}$ * \\ ${ }^{a}$ University of Ferrara Department of Architecture, via Ghiara 36, Ferrara 44121, Italy \\ ${ }^{b}$ BECQUEREL Electric, via Livatino 9, Reggio Emilia 42124,Italy
}

\begin{abstract}
In this paper we illustrate techniques and procedures for integrating common energy efficient services at Industrial Park level, in order to having larger equipment with higher performance, necessary to covering the required energy demand (by more effective services). Energy parks are responsible for big energy consumption: for this reason it is necessary to find smart solutions for managing energy outputs. We present a case of best-practice in Italy, in which the synergy between the SMEs (Small Medium Enterprises) leads to a sustainable development.
\end{abstract}

Keywords: Industrial Parks, renewable energies, ESCO - energy services companies

\section{Introduction}

Ecologically Equipped Productive Areas (EEPA) are disciplined in Italy by D.Lgs. 112/1998, that authorized Regions and local Municipalities to regulate industrial and ecological equipped areas, their identification and management [1].

Total electricity usage alone in industrial parks amounts up to 3,000 TWh per year, with a potential for up to $40-50 \%$ reduction [2]. Financial costs for energy usage in industries are estimated to be up to $10 \%$ of the gross added value for production intensive industries. High efficiencies and energy savings can be reached through cooperation between the companies in energy management. There is a large potential for energy savings in industrial parks. Independent interventions by single SMEs may provide a reduction of energy consumptions but the highest efficiency can be reached with an established collaboration between the companies involved on the energy management. The coordinator of these activities may be an Energy Service Company.

Energy Service Companies may lead the process of renovation by providing a renewable based and energy efficiency system developed on the latest technologies and solutions, reducing energy usage through energy cooperation and shared energy services. This potential requires a collaboration from the enterprises involved, the land owners and other stakeholders involved.

In Italy the name EEPA, acronym of Ecologically Equipped Productive Area, represents industrial, commercial and touristic districts in which the synergy between the SMEs leads to an increased competitiveness and a sustainable development.

\section{Industrial Parks Energy Cooperation Model}

L 20/2000 Define "Ecologically Equipped Industrial Areas" as "[those areas] equipped with infrastructures and services suitable to guarantee protection of health, environment and safety" and define performance goals related to healthiness of work sites, reduction of air and water pollution, waste

\footnotetext{
* Manuscript received June 28, 2018; revised March 3, 2019.

Corresponding author. Tel.: +39 0532 293633; E-mail address: silvia.brunoro@unife.it

doi: $10.12720 /$ sgce.8.3.257-262
} 
management and reutilization, reduction of energy consumption [3].

Energy service companies have a large role to play in providing businesses with high-value services in the form of heating, electricity, cooling, in order to master a modern, environmentally friendly, renewable based and energy efficient systems that relies on best-practices technologies and solutions. Recent examples of these are highly efficient, renewable and waste/residual recovery based systems and a demand response approach. [4].

The objective of Industrial Park Cooperation is to demonstrate that an integral mapping of the possibilities for a local energy system, including organizational, financial, legal, social and technical aspects, together with an active stakeholder approach will be able to overcome barriers and promote implementation. The strategy of intervention can be summarized in the following phases [5]:

- Involving target groups and key-actors such as industrial SMEs, ESCOs, land owners and regional governments by actively role in the project;

- Defining a systematic approach: how to optimally organize energy cooperation from a managerial point of view, based on an integral view of the needs of businesses, land owners and other important stakeholders;

- Reducing energy demand of industrial buildings by taking actions both in industrial processes as well as in the industrial buildings conditioning;

- Finding locally maximized solutions that makes the best use of local options for energy usage, storage and production;

- Covering the required energy demand by more effective services, by integrating common energy efficient services at Industrial Park level, in the way of having larger equipment with higher performance. As an example, using waste energy and local generation of renewable energy from free spaces (e.g. public spaces in the Industrial Park or in the immediate surroundings);

- Defining a business strategy focused on energy cooperation among businesses, and based on integrated energy services aimed to provide the deployment and maintenance of common services, for example, through ESCOs.

Strategy model steps are summarized in the following table:

Table 1. Industrial park energy cooperation model

\begin{tabular}{lll}
\hline Input & Objective & Actions \\
\hline Industrial park typology & Energy cooperation & $\begin{array}{l}\text { ACTIVE ACTIONS directly influencing the efficiency of the } \\
\text { energy transformation processes of the industrial supply } \\
\text { chains and adopting renewable sources }\end{array}$ \\
$\begin{array}{ll}\text { Energy simulation } \\
\text { Business model }\end{array}$ & $\begin{array}{l}\text { Shared energy services } \\
\text { Stakeholders } \\
\text { involvement } \\
\text { Replicable strategy }\end{array}$ & $\begin{array}{l}\text { Indirectly affecting positively the way of managing the } \\
\text { facilities demonstrating the savings achievable by sharing } \\
\text { services, logistic and interconnections }\end{array}$ \\
\hline
\end{tabular}

In the following paragraph, a best practice example to optimize enterprises and resources involved to obtain energy savings is described.

\section{The Case Study of Fabbrico and Rolo in Reggio Emilia, Italy}

The industrial district, located near Reggio Emilia (North Italy), started in the early 1990s when districts Campogrande 1 e Campogrande 2 have been installed; Campogrande 3, recently added to the cluster, better fulfil modern energy efficiency stardards at international and national level and environmental protection. [6] [7]. (Figure 1)

The Ecologically Equipped Productive Area (EEPA) of Fabbrico and Rolo, started in 2017 and involves Eighteen Limited companies from the Municipality of Rolo and Reggiolo, whose main activities are storage, wholesale and production of electromechanical and mechanical components for an approximately number of 1000 workers employed. In a first stage, some enterprises have made interventions in order to fulfil national standards and reduce energy consumption: efficient waste 
management, use of energy-saving lightbulbs, use of rainwater for irrigation and plumbing, optimization of productive and logistic processes, energy diagnosis for buildings and processes.

Most of the enterprises have a rental contract for the warehouses. Below an overview of the enterprises installed in the area.

Table 2. SMEs involved in Fabbrico and Rolo area

\begin{tabular}{|c|c|c|c|c|}
\hline SME & Main activity & $\begin{array}{l}\text { Workers } \\
\text { involved }\end{array}$ & $\begin{array}{l}\text { Electricity } \\
\text { consumptions }^{\mathrm{a}}\end{array}$ & $\begin{array}{l}\text { RES systems } \\
\text { already installed }\end{array}$ \\
\hline B Group S.r.l. & $\begin{array}{l}\text { Stocking, quality control } \\
\text { and sorting of clothes }\end{array}$ & 65 & Not available & no \\
\hline Butler Engineering S.p.A. & $\begin{array}{l}\text { Design and production of } \\
\text { different type of machines }\end{array}$ & 79 & Medium & no \\
\hline Covidien S.p.A & $\begin{array}{l}\text { Wholesale of medical and } \\
\text { orthopedic materials }\end{array}$ & 70 & High & $\begin{array}{l}\text { Photovoltaic } \\
\text { power plant on the } \\
\text { roof is not own by } \\
\text { the SME }\end{array}$ \\
\hline Cutters S.r.l. & Tiling tiles & - & Not available & no \\
\hline DHL S.p.A. & Shipping & 11 & Small & no \\
\hline F.1li Ferrari S.n.c. & Plastic molding & 17 & High & no \\
\hline Italbox S.p.A. & Packaging & 13 & Medium & $\begin{array}{l}\text { Photovoltaic } \\
\text { power plant on the } \\
\text { roof }(75 \mathrm{~kW})\end{array}$ \\
\hline Lo snodo - AMA & $\begin{array}{l}\text { Design and production of } \\
\text { components for plants and } \\
\text { machines }\end{array}$ & 15 & Not available & no \\
\hline MTA S.p.A. & $\begin{array}{l}\text { Electro } \\
\text { mechanical and electronic } \\
\text { components }\end{array}$ & 578 & High & $\begin{array}{l}\text { Photovoltaic } \\
\text { power plant on the } \\
\text { roof }(1.2 \mathrm{MW})\end{array}$ \\
\hline ODS S.r.l. & Wholesale of toys & 5 & Medium & no \\
\hline Officina meccanica Mecaf & Iron processing & 14 & Not available & no \\
\hline Optimas OE solutions S.r.l. & $\begin{array}{l}\text { Wholesale of plastics, nuts } \\
\text { and bolts }\end{array}$ & 31 & High & No \\
\hline Tecnica Forniture industriali S.r.1. & $\begin{array}{l}\text { Wholesale of agricultural } \\
\text { and industrial items }\end{array}$ & 7 & Medium & $\begin{array}{l}\text { Photovoltaic } \\
\text { power plant on the } \\
\text { roof }\end{array}$ \\
\hline Tecnica S.r.l. & Production of plastic pipes & 42 & Not available & no \\
\hline Urban Logistica S.r.l. & Stocking of goods & 10 & Not available & no \\
\hline Specialgom S.r.l. & Information not available & & & \\
\hline A.C.E.M. S.a.s. & Information not available & & & \\
\hline S.G.E. S.r.l. & Information not available & & & \\
\hline
\end{tabular}

Annual electricity demand of actual EEPA is estimated in $4.0 \mathrm{GWh}$ (annual energy bills). Main objective of the intervention is reducing energy demand of industrial buildings by taking actions both in industrial processes as well as in the industrial buildings conditioning. Therein, finding locally integral solutions that makes the best use of local options for energy usage, storage and production.

Energy of the grid comes from:

- Electricity: High voltage electricity is delivered to the perimeter of the area where it is first transform in Medium voltage and, in the last part of the grid, is delivered as Low voltage electricity.

- Gas: Underground gas system leads gas to the area, where it is distributed in medium pressure, through specific adapter, to the end users.

- Water: Potable water is delivered to the EEPA from the local stocking and distribution tank of Roncocesi (28 km from Rolo). 


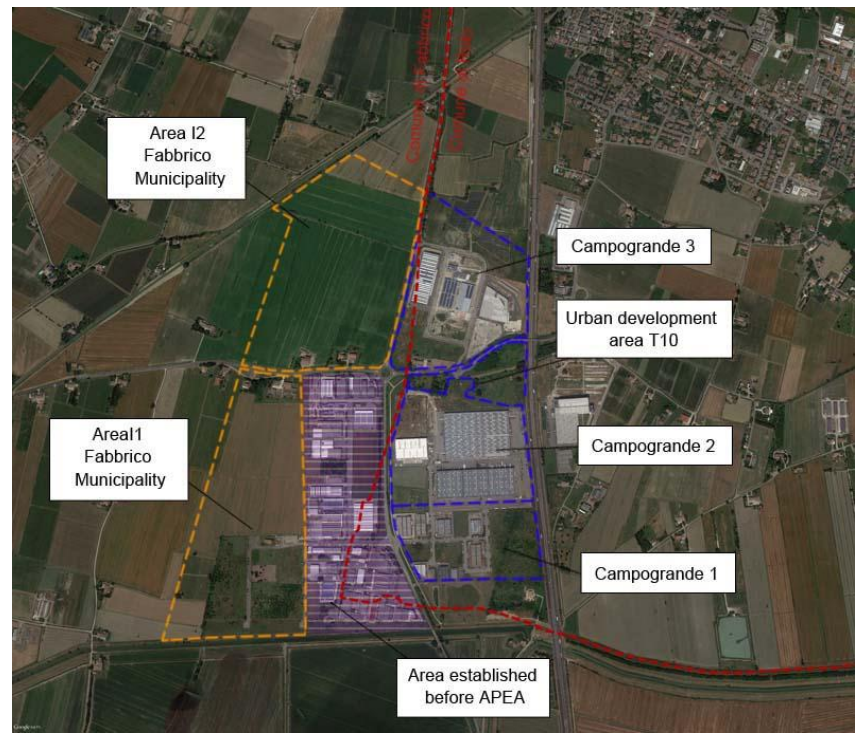

Fig. 1. Aerial photo of the ROLO industrial Park

Renewable energy is locally generated from a photovoltaic power plant (997.92 kWp installed), and from panels installed on the roofs of warehouses for an overall of 1.5 GigaWatt $(\mathrm{GW})$. The energy that is locally produced is used for the energy needs of the local SMEs or is sold to the grid: the revenues are used for the construction of other energy investments in the area other that photovoltaics or to cover costs and energy services actually provided to established companies. The use of energy that is locally produced prevent the emission of a remarkable amount of pollutants, as summarized in Table 3.

Table 3. Estimation of pollutant not released into the atmosphere

\begin{tabular}{lllllll}
\hline & Energy & \multicolumn{3}{c}{ Prevented Emissions (estimation) } \\
\hline $\begin{array}{l}\text { Reference } \\
\text { year }\end{array}$ & Produced Energy & $\mathrm{CO}_{2}$ & $\mathrm{SO}_{2}$ & $\mathrm{NO}_{\mathrm{x}}$ & $\mathrm{PM}$ & $\mathrm{Tep}$ \\
& $\mathrm{kWh}$ & $\mathrm{kg}$ & $\mathrm{kg}$ & $\mathrm{kg}$ & $\mathrm{kg}$ & $\mathrm{Tonn}$. \\
\hline 2013 & $1^{\prime} 305^{\prime} 261$ & $647^{\prime} 410$ & $1^{\prime} 214$ & 757 & 38 & 244 \\
2014 & $1^{\prime} 226^{\prime} 434$ & $608^{\prime} 312$ & $1^{\prime} 140$ & 711 & 35 & 230 \\
2015 & $1^{\prime 2} 233^{\prime} 780$ & $611^{\prime} 955$ & $1^{\prime} 147$ & 716 & 36 & 231 \\
2016 & $1^{\prime} 142^{\prime} 730$ & $566^{\prime} 795$ & $1^{\prime} 063$ & 663 & 33 & 214 \\
2017 & $1^{\prime} 143^{\prime} 120$ & $566^{\prime} 988$ & $1^{\prime} 063$ & 663 & 33 & 214 \\
\hline
\end{tabular}

\subsection{Activities and planned interventions}

Activities and interventions have been distributed in a ten years plan; actions planned are mainly focused on energetic aspects of SMEs management and secondly, when feasible, environmental aspects. First Energetic Plan envisage the following activities: public illumination and video surveillance networks in order to improve the safety of industries (workers and goods), an optical fiber network to optimize communication and internet connection. For local SMEs that will show participation and interest in this activity will be also provided an Energy Plan for medium and long term. In detail, the First Energetic Plan expects the following interventions[8]:

- Costs Management: Municipality of Rolo, as manager stakeholder, is in charge for spending management, including professionals involved and the activities needed to reach the established goals.

- Public illumination network: management and maintenance costs, renovation of existing network, implementation with energetically efficient devices for all industrial division Campogrande 1-2-3. Actual illumination network presents light fixtures wired and electrically connected with Sodium 
lamps, with golden yellow shades, installed on hot-dip galvanized metal tubular supports, partly with head-to-post connection, partly fixed to the end of curved pastorals. Local electric cabinets interact with a light flow regulator, which reduces the electrical power of the lamps' load up to $40 \%$ of the nominal value at night, with consequent energy savings both in economic terms and in environmental pollution. Rolo Municipality considers very important to focus attention on new lighting solutions, which further increase energy savings and at the same time contribute to the reduction of environmental pollution. The replacement of the current lighting points in operation with the innovative high efficiency LED lighting fixtures, with the aim of validating both the reduction of costs and the increase in the well-being of the community. The new network will be further implemented by setting up a Wi-Fi network and a webcam that covers the entire sector, as well as the "point-to-point" control function in order to minimize management and maintenance costs.

- Video surveillance network: implementation of surveillance system already installed and extension to the entire area. Interventions will include the installation of high-efficiency devices and will involve those SMEs that show their interest and contribution. The economic benefits that will be generated in terms of lower insurance costs and lower investments for safety equipment can be dedicated, from individual SMEs, to investments in the energy efficiency sector in the context of what will be the Environmental Energy Plans from them possibly shared with the Public Administration.

- Optical fiber network: local internet network cannot satisfy the daily demand, an update is then necessary. Most of the SMEs installed in the EEPA has a national or international relevance and need a certain and continue internet connection. The creation of fiber optic network for internet connection is a necessity shown by a large number of companies established within the EEPA. The fiber-optic network is already present in the urban center of the Municipality of Rolo; it would be a matter of extending the already existing network for a few $\mathrm{km}$ up to the EEPA. The actuator subject has been identified. The intervention will be implemented using the model of concession work: the concession is for the design, construction, maintenance, management in wholesale mode;

- SMEs Energy plans: mid and long-term energy plans will provide information about energy consumptions of buildings and processes, suggesting those interventions finalized to energy savings and renewable energy production in order to optimize the general energy demand. The intervention has started at the end of 2017 and will last 2 years, preliminary activities of data collection have been concluded. The cataloging of data collected was done in order to facilitate the subsequent elaboration of the plans. From meeting with companies carried out in 2016, an interest in energy plans was found by companies not subjected to Energy Audit.

- E-mobility: electric car sharing for local SMEs. All vehicles in the fleet will be powered by renewable energy (possibly from the local photovoltaic plant).

- Energy Help Desk: among the services offered by the program for companies established in the area, the Energy Help Desk is a useful tool to orient, inform and disseminate the themes related to saving and energy efficiency and to update the community about the goals achieved. The services are information-based on energy-saving issues, interventions and equipment to increase the energy efficiency of civil and commercial buildings.

- Other initiatives: once that the previous goals are accomplished and if other resources are available, other initiative with a high energetic potential will be realized (for example cogeneration plant, etc..)

\subsection{Energy saving data, costs, replicability of the model}

Total amount of the planned interventions has been estimated in $€ 964.235,32$. To ensure the maintenance of these standards, enterprises that will settle in the EEPA have to guarantee the following conditions:

- Collection and use of rainwater for irrigation of green areas;

- Installation of solar or photovoltaics panels to heat water;

- Use energy from renewable resources. 
Environmental and energetic benefit of electric car sharing powered by renewable and locally produced energy can be estimated in $4500 \mathrm{kWh} /$ year/car [8]; considering an average emission coefficient of $95 \mathrm{gCO}_{2} / \mathrm{km}$ [9], can be easily estimated a yearly reduction of $\mathrm{CO}_{2}$ emission of $813 \mathrm{kgCO}_{2}$.

The framework that is defined consists of methodology for SMEs cooperation, business models and joint energy services and is a replicable pattern for other industrial districts to facilitate the optimization of energy consumptions and to apply best practices or advice with the aim to increase the competitiveness of installed enterprises.

\section{Conclusions}

The use of joint contracting of mutualized energy services is a promising model for industrial parks, especially when businesses are not energy intensive and when they do not have the time, expertise and financial resources to develop such energy cooperation. Setting up an energy cooperation in whatever form will help industries and businesses to become more energy efficient.

The model demonstrate that legal, financial, technical, social and organizational barriers can be overcome. Moreover cooperation can be done via i.e. clustering buildings and processes, by energy exchange, collective production and joint contracting of mutualized energy services.

The synthesis of the lesson learned is a "best practice" methodology as reference for other European case to allow effective implementations.

\section{Acknowledgements}

The results have been achieved within the agreement between Rolo Municipality and the University of Ferrara-Department of Architecture and concerning the activity of technical support on energy management of EEPA. A special thanks to Becquerel Electric S.r.l. by courtesy of design and images of case study are published in this paper.

\section{References}

[1] D. Lgs. 31/03/1998, n.112 "Conferimento di funzioni e compiti amministrativi dello Stato alle Regioni ed agli Enti locali, in attuazione del capo I della legge 15/03/1997, n.59”. (Legislative Decree 31/03/1998, n.112 Conferral of functions and administrative tasks of the State to the Regions and Local Authorities, Chapter I).

[2] Bizzarri G., Piano Energetico Comune di Reggio Emilia, Essay, EdConsulta, 2008, ISBN 9788889156414 [Online]. Available::https://www.comune.re.it/retecivica/urp/retecivi.nsf/PESDocumentID/76B09D149CCD268FC125786A004065AB? opendocument (G. Bizzarri, Energetic Plan of Reggio Emilia Municipality).

[3] L.R. 24/03/2000, n.20 "Disciplina generale sulla tutela e l'uso del territorio" e s.m.i. (Regional Law 24/03/2000 General regulation on the protection and use of the territory).

[4] Brunoro S., Bizzarri G., Collective Self-Organized Housing: a research study To Optimize Building Technologies, Improve Efficiency And Reduce Building Consumptions, In: Sustainable development and planning IX, Vol. 226 of the WIT Transactions on Ecology and the Environment, Wit Press, Southampton, 2017, $73-84$.

[5] Bizzarri G., Local energy policies for Kyoto goals: Ecoabita protocol a key action to reduce energy consumption in residential sector, In: Energy and Buildings ,2011, 43, 2394 - 2403

[6] Emilia Romagna Region, Final Report POR-FESR 2007/2013 [Online]. Available: https://fesr.regione.emilia-romagna.it/porfesr/programmazione-precedente/documenti/RelazioneFinale20072013.pdf/@ @download/file/Relazione\%20Finale-20072013.pdf

[7] BECQUEREL s.r.l. WEBSITE [Online]. Available: http://www.becquerel.it/

[8] Programma Energetico e Ambientale APEA Rolo-Fabbrico, 2015 (Energy and Environmental Program EEPA Rolo-Fabbrico)

[9] Ministero dello Sviluppo Economico, Ministero dell'Ambiente e della Tutela del Territorio e del Mare, Ministero delle Infrastrutture e dei Trasporti - Guida al risparmio di carburanti e alle emissioni di CO2 delle auto, 2013 (Ministry of Economic Development, Ministry of Environment and Protection of Land and Sea, Ministry of Infrastructures and Transportation - Guide to fuel savings and CO2 emissions from cars, 2013) 